Technical Note for WRR:

\title{
An Analytical Solution for Transient Radial Flow through Unsaturated Fractured Porous Media
}

\author{
Yu-Shu Wu and Lehua Pan \\ Earth Sciences Division \\ Lawrence Berkeley National Laboratory \\ Berkeley CA 94720 USA
}

\begin{abstract}
This paper presents analytical solutions for one-dimensional radial transient flow through horizontal, unsaturated fractured rock formation. In these solutions, unsaturated flow through fractured media is described by a linearized Richards' equation, while fracture-matrix interaction is handled using the dual-continuum concept. Although linearizing Richards' equation requires a specially correlated relationship between relative permeability and capillary pressure functions for both fractures and matrix, these specially formed relative permeability and capillary pressure functions are still physically meaningful. These analytical solutions can thus be used to describe the transient behavior of unsaturated flow in fractured media under the described model conditions. They can also be useful in verifying numerical simulation results, which, as demonstrated in this paper, are otherwise difficult to validate.
\end{abstract}

Keywords: Richards' equation, unsaturated zone, fractured reservoirs, fracture-matrix interaction 


\section{Introduction}

In the past few decades, flow through unsaturated fractured rock, a special case of multiphase flow, has received a lot of attention because of subsurface environmental considerations. Quantitative analysis of flow in unsaturated fractured rock is often based on Richards' equation. Because of its nonlinear nature, Richards' equation solutions for general flow through fractured media may be obtained only with a numerical approach. On the other hand, analytical solutions, if available, provide more direct insight into the physics of unsaturated flow phenomena than numerical or laboratory studies, and they are often needed to examine and verify numerical model schemes or results.

For unsaturated flow through homogeneous single-porosity soils, many analytical solutions, both exact and approximate, have been developed based on different levels of Richards' equation linearization [e.g., Pullan, 1990; Warrick and Parkin, 1995; Basha, 1999; Philip, 1969; Zimmerman and Bodvarsson, 1995]. Despite the advances made so far, however, precise analytical solutions to Richards' equation remain intractable under general flow conditions, because of its known nonlinearity. In addition, it becomes more difficult to obtain an analytical solution for flow through unsaturated fractured porous media because of the additional complexity or inherent heterogeneity introduced by fracture-matrix interaction.

Recently, we presented a set of new analytical solutions for unsaturated flow within a single matrix block with fracture-matrix interaction [Wu and Pan, 2003]. These analytical solutions required a specially correlated relationship between relative permeability and capillary pressure functions. The present work extends our analytical solution approach to the entire fracture-matrix flow system, using a general dual-continuum approach. In this work, we show that it is possible to obtain analytical solutions if the specially correlated relative permeability and capillary pressure functions hold true for both fracture and matrix systems. In addition, we demonstrate that the new analytical solutions are very useful for checking numerical model results for unsaturated flow through 
fractured porous media.

\section{Mathematical Formulation}

The problems to be solved are cases of unsaturated radial flow in a horizontal and uniform fracture-matrix formation corresponding to a fully penetrating injection well, specified with either constant pressure or constant injection rate, respectively. The formation consists of identical cubic matrix blocks separated by a uniform three-dimensional fracture network, as in the Warren and Root model [Warren and Root, 1963], which can be approximated as two different continua. Furthermore, we assume that the two sets of capillary pressure and relative permeability functions for fracture and matrix, respectively, are in the form:

$$
\mathrm{k}_{\mathrm{r} \xi}\left(\mathrm{S}_{\xi}\right)=\mathrm{C}_{\mathrm{k} \xi}\left(\mathrm{S}_{\xi}^{*}\right)^{\alpha_{\xi}}
$$

and

$$
\mathrm{P}_{\mathrm{c} \xi}\left(\mathrm{S}_{\xi}\right) \equiv \mathrm{P}_{\mathrm{g} \xi}-\mathrm{P}_{\mathrm{w} \xi}=\mathrm{C}_{\mathrm{p} \xi}\left(\mathrm{S}_{\xi}^{*}\right)^{-\beta_{\xi}}
$$

where subscript $\xi$ is an index for fracture $(\xi=\mathrm{F})$ or matrix $(\xi=\mathrm{M}) ; \mathrm{P}_{\mathrm{g} \xi}$ is constant air (or gas) pressure in fractures or the matrix; $\mathrm{P}_{\mathrm{w} \xi}$ is liquid water pressure in fractures or the matrix, respectively; $C_{k \xi}$ and $C_{p \xi}$ are coefficients $(\mathrm{Pa}), \alpha_{\xi}$ and $\beta_{\xi}$ are exponential constants of relative permeability and capillary pressure functions, respectively, with fracture and matrix systems; and $\mathrm{S}_{\xi}^{*}$ is the effective fracture or matrix water saturation,

$$
\mathrm{S}_{\xi}^{*}=\frac{\mathrm{S}_{\xi}-\mathrm{S}_{\xi \mathrm{r}}}{1-\mathrm{S}_{\xi \mathrm{r}}}
$$


with $S_{\xi_{\mathrm{r}}}$ being the residual water saturation in fracture and matrix systems, respectively.

If the following conditions,

$$
\alpha_{\xi}=\beta_{\xi}+1
$$

are satisfied for both fractures and matrix, Richards' equation can be readily linearized for flow through both fractures or the matrix [Wu and Pan, 2003]. The linearized governing equation for unsaturated radial flow (ignoring gravity effect and compressibility of water and rock) through the fractures can be derived using a mass balance on a control volume and the dual-continuum concept (see Appendix A), as follows:

$$
\frac{\partial^{2} \mathrm{~S}_{\mathrm{F}}}{\partial \mathrm{r}^{2}}+\frac{1}{\mathrm{r}} \frac{\partial \mathrm{S}_{\mathrm{F}}}{\partial \mathrm{r}}-\left.\frac{6 \phi_{\mathrm{M}}}{\mathrm{B} \phi_{\mathrm{F}}} \frac{\mathrm{D}_{\mathrm{M}}}{\mathrm{D}_{\mathrm{F}}} \frac{\partial \mathrm{S}_{\mathrm{M}}}{\partial \mathrm{x}}\right|_{\mathrm{z}=\mathrm{B} / 2}=\frac{1}{\mathrm{D}_{\mathrm{F}}} \frac{\partial \mathrm{S}_{\mathrm{F}}}{\partial \mathrm{t}}
$$

(If not described, the symbols for variables and parameters in Equation (5) or in the following equations are defined in the appendixes.) The third term on the left-hand side of Equation (5) represents flow exchange terms on the local matrix interface between fracture and matrix systems, describing the continuity in mass flux.

For flow inside the matrix, we use a 1-D spherical-flow approximation [ $W u$ and Pan, 2003], and the unsaturated flow inside a cubic matrix block is then governed by

$$
\frac{\partial^{2} S_{M}}{\partial x^{2}}+\frac{2}{x} \frac{\partial S_{M}}{\partial x}=\frac{1}{D_{M}} \frac{\partial S_{M}}{\partial t}
$$

The initial conditions within fractures and matrix systems are uniform: 


$$
\left.\mathrm{S}_{\xi}\right|_{\mathrm{t}=0}=\mathrm{S}_{\xi \mathrm{r}}
$$

Note here that for simplicity initial saturations in fractures and the matrix are set to their residual values, respectively.

The first inner boundary condition is that the wellbore be specified with constant saturation:

$$
\mathrm{S}_{\mathrm{F}}\left(\mathrm{r}=\mathrm{r}_{\mathrm{w}}, \mathrm{t}\right)=\mathrm{S}_{0}
$$

and the second is that the injection rate be constatnt:

$$
-\left.\frac{2 \pi r_{w} h_{\mathrm{F}} \mathrm{C}_{\mathrm{kF}} \mathrm{C}_{\mathrm{pF}}}{\mu_{\mathrm{w}}} \frac{\partial \mathrm{S}_{\mathrm{F}}^{*}}{\partial \mathrm{r}}\right|_{\mathrm{r}=\mathrm{r}_{\mathrm{w}}}=\mathrm{q}
$$

Far away from the well, the boundary condition in fractures remains at its initial condition

$$
\mathrm{S}_{\mathrm{F}}(\mathrm{r}=\infty, \mathrm{t})=\mathrm{S}_{\mathrm{Fr}}
$$

At the matrix surface, the continuity in pressure or capillary pressure is enforced:

$$
\mathrm{P}_{\mathrm{cF}}(\mathrm{r}, \mathrm{t})=\mathrm{P}_{\mathrm{cM}}(\mathrm{x}=\mathrm{B} / 2, \mathrm{t} ; \mathrm{r})
$$

while at the matrix block center, a zero-gradient condition is maintained for symmetry:

$$
\frac{\partial S_{M}(x=0, t ; r)}{\partial x}=0
$$

\section{Analytical Solutions}


In the following dimensionless variables, the dimensionless distances are defined as

$$
\begin{aligned}
& r_{D}=\frac{r}{r_{w}} \\
& x_{D}=\frac{2 x}{B}
\end{aligned}
$$

and the dimensionless time is

$$
t_{D}=\frac{D_{F} t}{(B / 2)^{2}}
$$

The normalized (or scaled) water saturation is

$$
\mathrm{S}_{\xi \mathrm{D}}=\mathrm{S}_{\xi}^{*}=\frac{\mathrm{S}_{\xi}-\mathrm{S}_{\xi \mathrm{r}}}{1-\mathrm{S}_{\xi \mathrm{r}}}
$$

In terms of these dimensionless variables, the solution for the normalized matrix saturation in the Laplace space is given by (Appendix B):

$$
\bar{S}_{\mathrm{MD}}=\mathrm{A}_{4} \frac{\overline{\mathrm{S}}_{\mathrm{FD}}}{\sqrt{\mathrm{x}_{\mathrm{D}}}} \frac{\mathrm{I}_{1 / 2}\left(\sigma \mathrm{x}_{\mathrm{D}}\right)}{\mathrm{I}_{1 / 2}(\sigma)}=\mathrm{A}_{4} \frac{\overline{\mathrm{S}}_{\mathrm{FD}}}{\mathrm{x}_{\mathrm{D}}} \frac{\sinh \left(\sigma \mathrm{x}_{\mathrm{D}}\right)}{\sinh (\sigma)}
$$

where $\sigma=\sqrt{\mathrm{A}_{3} \mathrm{p}}$ and $\mathrm{I}_{1 / 2}$ is the modified Bessel function of the first kind.

$\overline{\mathrm{S}}_{\mathrm{FD}}$ is the solution of the normalized fracture saturation in the Laplace space, defined differently for the two well boundary conditions (Appendix B). The solution $\overline{\mathrm{S}}_{\mathrm{FD}}$ with constant water saturation at the wellbore, in Equation (8), is given by: 


$$
\bar{S}_{\mathrm{FD}}=\frac{\mathrm{S}_{0 \mathrm{D}}}{\mathrm{p}} \frac{\mathrm{K}_{0}\left(\sqrt{\mathrm{x}_{2}} \mathrm{r}_{\mathrm{D}}\right)}{\mathrm{K}_{0}\left(\sqrt{\mathrm{x}_{2}}\right)}
$$

where $x_{2}=A_{1} A_{4}[\sigma \operatorname{coth} \sigma-1]+A_{2} p$. For the case of constant flow rate as defined in Equation (9), the solution $\overline{\mathrm{S}}_{\mathrm{FD}}$ is

$$
\overline{\mathrm{S}}_{\mathrm{FD}}=\frac{\mathrm{q}_{\mathrm{D}}}{\mathrm{p}} \frac{\mathrm{K}_{0}\left(\sqrt{\mathrm{x}_{2}} \mathrm{r}_{\mathrm{D}}\right)}{\sqrt{\mathrm{x}_{2}} \mathrm{~K}_{1}\left(\sqrt{\mathrm{x}_{2}}\right)}
$$

In the solutions above, constants $\mathrm{A}_{1}, \mathrm{~A}_{2}, \mathrm{~A}_{3}$, and $\mathrm{A}_{4}$ are defined in Appendix $\mathrm{B} ; \mathrm{K}_{0}$ and $\mathrm{K}_{1}$ is the modified Bessel function of the second kind for zero and first order, respectively.

Equations (17), (18), and (19) constitute the solutions in the Laplace space for normalized fracture and matrix saturations under two types of inner-well-boundary conditions. To apply these solutions, we use the Stehfest [1970] algorithm to invert these solutions from the Laplace space to the real space.

\section{Application}

First, the analytical solutions of Equations (18) and (19) were used to calculate type curves that deal with transient flow through a fully penetrating well into a uniform, horizontal fractured formation, which is $10 \mathrm{~m}$ thick and radially infinite. The fractured formation consists of uniform, identical $1 \times 1$ $\times 1 \mathrm{~m}$ cubes of matrix blocks, surrounding by a uniform, 3-D fracture network, identical to the Warren and Root conceptual model. The basic fracture-matrix and fluid parameters used for the example are listed in Table 1. A numerical inversion algorithm [Stehfest, 1970] was used in calculating the analytical solutions. During the numerical Laplace inversion, the Stehfest's method was found to work well, and the inverted solutions were verified by comparison with numerical simulations and asymptotic solutions through many numerical experiments. 
The results are depicted as normalized liquid saturation in fractures versus the dimensionless radial distance from the well at different dimensionless times, in Figure 1 (a constant saturation at the wellbore) and Figure 2 (a constant injection rate at well), respectively. These two type curves can be used for examining numerical model results for the same fracture-matrix flow system.

The analytical solutions were then used to assess the performance of the double-porosity and MINC approaches in simulating fracture-matrix interaction in unsaturated fracture rocks. Note that the double-porosity model represents the matrix by one single gridblock, whereas the MINC concept subdivides a matrix block into many single or multidimensional or nested cells [Pruess and Narasimhan, 1985]. Numerical simulations are performed using a numerical reservoir simulator [Wu et al., 1996]. Note that the governing equation solved in numerical modeling is still the original Richards' equation, instead of the linearized forms of Equations (5) and (6). The same relative permeability and capillary functions as those of Equations (1) and (2) in the analytical solutions are input to the numerical model.

In the second application, the radial single-well flow system used is basically the same as that in the first example. Rock and fluid properties are also given in Table 1. In the numerical model, however, the uniform, horizontal, radially infinite formation is represented by a finite radial system with an outer boundary radius of $1,000 \mathrm{~m}$. It is large enough such that the wetting front does not reach the boundary at the end of simulation. Two numerical grids, a double-porosity mesh and a MINC one, are generated for the radial symmetric formation. The double-porosity grid represents the matrix system by one mesh locally [Warren and Root, 1963], while the MINC grid subgrids each matrix block with 7 nested cells, for better numerical accuracy in estimating fracture-matrix flow [Pruess and Narasimhan, 1985].

Figure 3 shows the saturation distribution along the fractures in the radial direction at time of 0.1 and 10 days, respectively, simulated by the analytical, double-porosity, and MINC modeling results. Note that the physical process simulated in this example is extremely nonlinear and dynamic. The initial liquid saturations are at residual values for both fracture and matrix systems. At the beginning, 
the boundary saturation for fractures at the wellbore jumps to one (thus, flow rate at the well becomes infinitely large). Once imbibed into the fractures, the liquid will be competed by two forces in two directions, one for continuous flow along fractures away from the well, and the other sucked into dry matrix blocks.

The numerical model results, shown in Figure 3, indicate that the MINC model does a much better job in matching the analytical solutions than the double-porosity model. This implies that in this case the MINC concept better captures these physical processes by considering capillary gradients at matrix surface and inside matrix blocks. However, Figure 3 clearly shows that even the MINC simulations cannot match the analytical results very well. The reason behind this discrepancy is that the matrix surface is subject to dynamic boundary conditions, i.e., varying fracture saturation or capillary forces, which occurs at the upstream boundary for initializing imbibition into the matrix. Using a dual-continuum numerical approach [Wu and Pan, 2003], extremely refined spatial discretization is required to model imbibing processes accurately under dynamic upstream boundary conditions.

Although the analytical solutions presented above are obtained under very strict assumptions (i.e., specially correlated relations between relative permeability and capillary functions for both fractures and the matrix, as well as negligible gravity effects), the relative permeability and capillary functions of Equations (1) and (2) are not only physically meaningful, but also among the most widely used relations [Honarpour et. al., 1986]. In particular, for numerical models based on the dual-continuum method (including double-porosity, MINC, and multiple-porosity, models [e.g., Kazemi, 1969; Pruess and Narasimhan, 1985; Wu and Pruess, 1988]), handling fracture-matrix interactions under different flow conditions is a key issue and its verification remains a challenge [Kazeme et al., 1992] because of the dearth of analytical solutions for unsaturated flow through fracture-matrix media. Since the treatment of fracture-matrix interaction in this analytical model is based rigorously on the dual-continuum concept, the analytical solutions obtained can be useful in evaluating numerical model results from dualcontinuum models, as shown above. 


\section{Concluding Remarks}

This paper shows that with specially formed capillary pressure and relative permeability functions, it is possible to obtain analytical solutions for transient unsaturated flow in fractured-matrix systems using the commonly used dual-continuum concept. With the analytical solutions provided in the Laplace space, analytical solutions in real space can be readily obtained using numerical inversion techniques. The analytical-solution approach of this work can be readily extended to other boundary conditions or different flow geometries, such as linear and multidimensional unsaturated flow through fractured porous formation.

The analytical solutions, though limited by the assumptions for their applications, can be used to obtain some insight into the physics of transient flow processes related to fracture-matrix interactions. As demonstrated in this work, these analytical solutions are very useful in verifying numerical models and their results for describing flow through unsaturated fractured rock, especially the flow through a fracture-matrix interface, which is otherwise very difficult to evaluate.

\section{Acknowledgments}

The authors would like to thank Yingqi Zhang and Dan Hawkes for their review of this manuscript. The authors are also like to thank their colleague, George Moridis, for providing the computing program for numerical Laplace inversion. This work was supported in part by the Director, Office of Civilian Radioactive Waste Management, U. S. Department of Energy, through Memorandum Purchase Order QA-B004220RB3X between Bechtel SAIC Company, LLC, and the Ernest Orlando Lawrence Berkeley National Laboratory (Berkeley Lab). The support is provided to Berkeley Lab through the U.S. Department of Energy Contract No. DEAC03-76SF00098 


\section{Reference}

Basha, H. A., multidimensional linearized nonsteady infiltration with prescribed boundary conditions at the soil surface, Water Resour. Res., 35(1), 75-83, 1999.

Honarpour, M., L. Koederitz, and A. H. Harvey, Relative permeability of petroleum reservoirs, CRC Press, Inc., Boca Raton, Florida, 1986.

Lai, C. H., G. S. Bodvarsson, C. F. Tsang, and P. A. Witherspoon, A new model for well test data analysis for naturally fractured reservoirs, SPE-11688, Presented at the 1983 California Regional Meeting, Ventura, California, March, 1983.

Kazemi, H., J. R. Dilman, and A. E. Elsharkawy, A nalytical and numerical solution of oil recovery from fractured reservoirs with empirical transfer functions, SPE Reservoir Engineering, 219-227, 1992.

Kazemi, $\mathrm{H}$., Pressure transient analysis of naturally fractured reservoirs with uniform facture distribution, Soc. Pet. Eng. J., 451-62, Trans., AIM E, 246, 1969.

Philips, J. R., Theory of Infiltration, Adv. Hydrosci., 5, 215-296, 1969.

Pruess, K., Multiphase flow in fractured rocks-some lessons learned from mathematical models, "Dynamics of Fluids in Fractured Rocks, Concepts and Recent Advances", Edited by B. Faybishenko, P. A. Witherspoon and S. M. Benson, A GU Geophysical M onograph 122, A merican Geophysical U nion, W ashington, DC, 225-234, 2000.

Pruess, K. and T. N. Narasimhan, A practical method for modeling fluid and heat flow in fractured porous media, Soc. Pet. Eng. J., 25, 14-26, 1985.

Pullan, A. J., The quasilinear approximation for unsaturated porous media flow, Water Resour. Res., 26 (6), 1219-1234, 1990.

Stehfest, H., Numerical inversion of Laplace transforms, Communications of the ACM, 13, No. 1, 47-49, 1970.

Warren, J. E. and P. J. Root, The behavior of naturally fractured reservoirs, Soc. Pet. Eng. J., 245-255, Transactions, AIM E, 228, 1963.

Warrick, A. W., and G. W. Parkin, Analytical solution for one-dimensional drainage: Burgers' and simplified forms, Water Resour. Res., 31(11), 2891-2894, 1995. 
Wu, Y. S. and L. Pan, Special relative permeability functions with analytical aolutions for transient flow into unsaturated rock matrix, Water Resour. Res., 39(4), 3-1-3-9, 2003.

Wu, Y. S., C. F. Ahlers, P. Fraser, A. Simmons, and K. Pruess, Software qualification of selected TOUGH2 modules, Report, LBNL-39490, Lawrence Berkeley National Laboratory, Berkeley, CA, 1996.

W u, Y. S. and K. Pruess, A multiple-porosity method for simulation of naturally fractured petroleum reservoirs, SPE Reservoir Engineering, 3, 327-336, 1988.

Zimmerman, R. W. and G. S. Bodvarsson, Effective block size for imbibition or adsorption in dual-porosity media, Geophysical Research Letters, 22(11), 1461-1464, 1995.

\section{Appendix A. Derivation of Governing Equations}

Let us consider a situation of unsaturated flow in a horizontal and uniform fractured-matrix formation. Fractures and rock matrixes are lumped into two different continua, with matrix being identical cubic blocks, separated by uniform three-dimensional fracture network, as in the Warren and Root model. Furthermore, gravity effects are ignored and incompressible liquid flows through a single well into a radial infinite system.

The governing equations of unsaturated radial flow through such a fracture-matrix system can be derived using a mass balance on the control volume and the dual-continuum concept [Lai et al. 1983]. In the radial system, a control volume at a radial distance of $r$ from the well is defined as

$$
\mathrm{V}_{\mathrm{n}}=\pi\left((\mathrm{r}+\mathrm{dr})^{2}-\mathrm{r}^{2}\right) \mathrm{h} \approx 2 \pi \mathrm{rhdr}
$$

The interface area $A_{c}$ between rock matrix blocks and surrounding fractures within the control volume $\mathrm{V}_{\mathrm{n}}$ is written as

$$
A_{c}=6 B^{2}\left(V_{n} / B^{3}\right)
$$

where $\mathrm{B}$ is fracture spacing or the dimension of matrix cubes. 
Mass balance for the incompressible fluid within the control volume requires that:

$$
\mathrm{q}_{\mathrm{r}} \mathrm{A}_{\mathrm{r}}-\left[\mathrm{q}_{\mathrm{r}} \mathrm{A}_{\mathrm{r}}+\frac{\partial}{\partial \mathrm{r}}\left(\mathrm{q}_{\mathrm{r}} \mathrm{A}_{\mathrm{r}}\right) \mathrm{dr}\right]+\left[\mathrm{q}_{\mathrm{x}} \mathrm{A}_{\mathrm{c}}\right]_{\mathrm{x}=\mathrm{B} / 2}=\frac{\partial\left(\mathrm{V}_{\mathrm{n}} \phi_{\mathrm{F}} \mathrm{S}_{\mathrm{F}}\right)}{\partial \mathrm{t}}
$$

where $\mathrm{x}$ is the distance from a nested cross-sectional surface within the matrix block (having an equal distance to the matrix surface) to the center of the cube (i.e., a one-dimensional spherical coordinate with its center within the matrix block); and $\mathrm{q}_{\mathrm{r}}$ and $\mathrm{q}_{\mathrm{x}}$ are Darcy's flow rate along $\mathrm{r}$ and $\mathrm{x}$ directions, respectively, calculated as

$$
\mathrm{q}_{\mathrm{r}}=-\frac{\mathrm{k}_{\mathrm{F}} \mathrm{k}_{\mathrm{rF}}}{\mu_{\mathrm{w}}} \frac{\partial \mathrm{P}_{\mathrm{wF}}}{\partial \mathrm{r}}=\frac{\mathrm{k}_{\mathrm{F}} \mathrm{k}_{\mathrm{rF}}}{\mu_{\mathrm{w}}} \frac{\partial \mathrm{P}_{\mathrm{cF}}}{\partial \mathrm{r}}=-\frac{\mathrm{k}_{\mathrm{F}} \mathrm{C}_{\mathrm{kF}} \mathrm{C}_{\mathrm{pF}}}{\mu_{\mathrm{w}}\left(1-\mathrm{S}_{\mathrm{Fr}}\right)} \frac{\partial \mathrm{S}_{\mathrm{F}}}{\partial \mathrm{r}}
$$

and

$$
\mathrm{q}_{\mathrm{x}}=-\frac{\mathrm{k}_{\mathrm{M}} \mathrm{k}_{\mathrm{rM}}}{\mu_{\mathrm{w}}} \frac{\partial \mathrm{P}_{\mathrm{wM}}}{\partial \mathrm{r}}=\frac{\mathrm{k}_{\mathrm{M}} \mathrm{k}_{\mathrm{rM}}}{\mu_{\mathrm{w}}} \frac{\partial \mathrm{P}_{\mathrm{cM}}}{\partial \mathrm{r}}=-\frac{\mathrm{k}_{\mathrm{M}} \mathrm{C}_{\mathrm{kM}} \mathrm{C}_{\mathrm{pM}}}{\mu_{\mathrm{w}}\left(1-\mathrm{S}_{\mathrm{Mr}}\right)} \frac{\partial \mathrm{S}_{\mathrm{M}}}{\partial \mathrm{r}}
$$

Substituting (A-4) and (A-5), as well as, radial-cross area $A_{r}=2 \pi$ rh into (A-3), yields

$$
\frac{\mathrm{k}_{\mathrm{F}} \mathrm{C}_{\mathrm{kF}} \mathrm{C}_{\mathrm{pF}}}{\mu_{\mathrm{w}}\left(1-\mathrm{S}_{\mathrm{Fr}}\right)}\left(\frac{\partial^{2} \mathrm{~S}_{\mathrm{F}}}{\partial \mathrm{r}^{2}}+\frac{1}{\mathrm{r}} \frac{\partial \mathrm{S}_{\mathrm{F}}}{\partial \mathrm{r}}\right)-\left.\frac{6}{\mathrm{~B}} \frac{\mathrm{k}_{\mathrm{M}} \mathrm{C}_{\mathrm{kM}} \mathrm{C}_{\mathrm{pM}}}{\mu_{\mathrm{w}}\left(1-\mathrm{S}_{\mathrm{Mr}}\right)} \frac{\partial \mathrm{S}_{\mathrm{M}}}{\partial \mathrm{x}}\right|_{\mathrm{z}=\mathrm{B} / 2}=\phi_{\mathrm{F}} \frac{\partial \mathrm{S}_{\mathrm{F}}}{\partial \mathrm{t}}
$$

If we define $\mathrm{D}_{\xi}$ as soil-water or moisture diffusivity ( $W u$ and Pan, 2003):

$$
\mathrm{D}_{\xi}=\frac{\mathrm{k}_{\xi} \mathrm{k}_{\mathrm{r} \xi}}{\phi_{\xi} \mu_{\mathrm{w}}} \frac{\partial \mathrm{P}_{\mathrm{w} \xi}}{\partial \mathrm{S}_{\mathrm{w}}}=\frac{\mathrm{k}_{\xi} \mathrm{C}_{\mathrm{k} \xi} \mathrm{C}_{\mathrm{p} \xi}}{\phi_{\xi} \mu_{\mathrm{w}}\left(1-\mathrm{S}_{\xi \mathrm{r}}\right)}
$$


with a dimension of $\mathrm{m}^{2} / \mathrm{s}$. We will thus derive the linearized flow governing equation of (5) for flow through the fractures.

\section{Appendix B. Derivation of Analytical Solutions}

In terms of these dimensionless variables, the two governing equations become:

$$
\frac{\partial^{2} \mathrm{~S}_{\mathrm{FD}}}{\partial \mathrm{r}_{\mathrm{D}}^{2}}+\frac{1}{\mathrm{r}_{\mathrm{D}}} \frac{\partial \mathrm{S}_{\mathrm{FD}}}{\partial \mathrm{r}_{\mathrm{D}}}-\left.\mathrm{A}_{1} \frac{\partial \mathrm{S}_{\mathrm{MD}}}{\partial \mathrm{x}_{\mathrm{D}}}\right|_{\mathrm{z}=\mathrm{B} / 2}=\mathrm{A}_{2} \frac{\partial \mathrm{S}_{\mathrm{FD}}}{\partial \mathrm{t}_{\mathrm{D}}}
$$

and

$$
\frac{\partial^{2} S_{M D}}{\partial x_{D}^{2}}+\frac{2}{x_{D}} \frac{\partial S_{M D}}{\partial x_{D}}=A_{3} \frac{\partial S_{M D}}{\partial t_{D}}
$$

where

$$
\begin{aligned}
& \mathrm{A}_{1}=\frac{12 \mathrm{D}_{\mathrm{M}} \phi_{\mathrm{M}} \mathrm{r}_{\mathrm{w}}^{2}}{\mathrm{D}_{\mathrm{f}} \phi_{\mathrm{F}} \mathrm{B}^{2}} \frac{1-\mathrm{S}_{\mathrm{Mr}}}{1-\mathrm{S}_{\mathrm{Fr}}} \\
& \mathrm{A}_{2}=\frac{4 \mathrm{r}_{\mathrm{w}}^{2}}{\mathrm{~B}^{2}}
\end{aligned}
$$

and

$$
\mathrm{A}_{3}=\frac{\mathrm{D}_{\mathrm{F}}}{\mathrm{D}_{\mathrm{M}}}
$$

The initial and boundary conditions in turn become:

$$
\left.\mathrm{S}_{\xi \mathrm{D}}\right|_{\mathrm{t}_{\mathrm{D}}=0}=0
$$

The boundary conditions of constant saturation at the well become 


$$
\mathrm{S}_{\mathrm{FD}}\left(\mathrm{r}_{\mathrm{D}}=1, \mathrm{t}_{\mathrm{D}}\right)=\frac{\mathrm{S}_{0}-\mathrm{S}_{\mathrm{Fr}}}{1-\mathrm{S}_{\mathrm{Fr}}}=\mathrm{S}_{0 \mathrm{D}}
$$

The constant rate condition turns into

$$
-\left.\frac{\partial S_{\mathrm{FD}}}{\partial \mathrm{r}_{\mathrm{D}}}\right|_{\mathrm{r}_{\mathrm{D}}=1}=\frac{\mathrm{q} \mu_{\mathrm{w}}}{2 \pi \mathrm{hk}_{\mathrm{F}} \mathrm{C}_{\mathrm{kF}} \mathrm{C}_{\mathrm{pF}}}=\mathrm{q}_{\mathrm{D}}
$$

Far away from the well,

$$
\mathrm{S}_{\mathrm{FD}}\left(\mathrm{r}_{\mathrm{D}}=\infty, \mathrm{t}_{\mathrm{D}}\right)=0
$$

At the matrix surface, the continuity in pressure becomes

$$
\mathrm{C}_{\mathrm{pF}} \mathrm{S}_{\mathrm{FD}}^{-1}\left(\mathrm{r}_{\mathrm{D}}, \mathrm{t}_{\mathrm{D}}\right)=\mathrm{C}_{\mathrm{pM}} \mathrm{S}_{\mathrm{MD}}^{-1}\left(\mathrm{x}_{\mathrm{D}}=1, \mathrm{t}_{\mathrm{D}} ; \mathrm{r}_{\mathrm{D}}\right)
$$

or

$$
\mathrm{S}_{\mathrm{MD}}\left(\mathrm{x}_{\mathrm{D}}=1, \mathrm{t}_{\mathrm{D}} ; \mathrm{r}_{\mathrm{D}}\right)=\frac{\mathrm{C}_{\mathrm{pM}}}{\mathrm{C}_{\mathrm{pF}}} \mathrm{S}_{\mathrm{FD}}\left(\mathrm{r}_{\mathrm{D}}, \mathrm{t}_{\mathrm{D}}\right)
$$

Note that the linear relationship for the continuity in pressure on the matrix surface requires the exponential constants of capillary $\beta_{\xi}=1$ for both fracture and matrix media. At the matrix block center,

$$
\frac{\partial \mathrm{S}_{\mathrm{MD}}\left(\mathrm{x}_{\mathrm{D}}=0, \mathrm{t}_{\mathrm{D}} ; \mathrm{r}_{\mathrm{D}}\right)}{\partial \mathrm{x}_{\mathrm{D}}}=0
$$

Applying the Laplace transformation to Equations (B-1) and (B-2) and incorporating the initial condition (B-6) yield: 


$$
\frac{\partial^{2} \overline{\mathrm{S}}_{\mathrm{FD}}}{\partial \mathrm{r}_{\mathrm{D}}^{2}}+\frac{1}{\mathrm{r}_{\mathrm{D}}} \frac{\partial \overline{\mathrm{S}}_{\mathrm{FD}}}{\partial \mathrm{r}_{\mathrm{D}}}-\left.\mathrm{A}_{1} \frac{\partial \overline{\mathrm{S}}_{\mathrm{MD}}}{\partial \mathrm{x}_{\mathrm{D}}}\right|_{\mathrm{z}=\mathrm{B} / 2}-\mathrm{pA}_{2} \overline{\mathrm{S}}_{\mathrm{FD}}=0
$$

and

$$
\frac{\partial^{2} \overline{\mathrm{S}}_{\mathrm{MD}}}{\partial \mathrm{x}_{\mathrm{D}}^{2}}+\frac{2}{\mathrm{x}_{\mathrm{D}}} \frac{\partial \overline{\mathrm{S}}_{\mathrm{MD}}}{\partial \mathrm{x}_{\mathrm{D}}}-\mathrm{pA}_{3} \overline{\mathrm{S}}_{\mathrm{MD}}=0
$$

In Equations (B-12) and (B-13), $\overline{\mathrm{S}}_{\xi \mathrm{D}}$ is the Laplace transformed normalized saturation, and $\mathrm{p}$ is the Laplace variable. The transformed boundary conditions are:

$$
\begin{aligned}
& \left.\overline{\mathrm{S}}_{\mathrm{FD}}\right|_{\mathrm{r}_{\mathrm{D}}=1}=\mathrm{S}_{0 \mathrm{D}} / \mathrm{p} \\
& -\left.\frac{\partial \overline{\mathrm{S}}_{\mathrm{FD}}}{\partial \mathrm{r}_{\mathrm{D}}}\right|_{\mathrm{r}_{\mathrm{D}}=1_{\mathrm{w}}}=\mathrm{q}_{\mathrm{D}} / \mathrm{p} \\
& \left.\overline{\mathrm{S}}_{\mathrm{FD}}\right|_{\mathrm{r}_{\mathrm{D}}=\infty}=0
\end{aligned}
$$

At the matrix surface,

$$
\left.\overline{\mathrm{S}}_{\mathrm{MD}}\right|_{\mathrm{x}_{\mathrm{D}}=1}=\frac{\mathrm{C}_{\mathrm{pM}}}{\mathrm{C}_{\mathrm{pF}}} \overline{\mathrm{S}}_{\mathrm{FD}}=\mathrm{A}_{4} \overline{\mathrm{S}}_{\mathrm{FD}}
$$

with $\mathrm{A}_{4}=\mathrm{C}_{\mathrm{pM}} / \mathrm{C}_{\mathrm{pF}}$, and at the matrix block center,

$$
\frac{\partial \overline{\mathrm{S}}_{\mathrm{MD}}\left(\mathrm{x}_{\mathrm{D}}=0, \mathrm{t}_{\mathrm{D}} ; \mathrm{r}_{\mathrm{D}}\right)}{\partial \mathrm{x}_{\mathrm{D}}}=0
$$

The solution for the mormalized matrix saturation of Equations (B-13), (B-17), and (B-18) in the 
Laplace space is given by Equation (17).

Using Equation (17) in Equation (B-1), the solution of the normalized fracture saturation with constant water saturation at the well of (B-1), (B-14), and (B-16) is given by equation (18). For the case of constant injection rate at the well, the solution for Equations (B-1), (B-15), and (B-16) is given by Equation (19).

Table 1. Parameters for the type curves of fracture liquid saturation

\begin{tabular}{|l|l|l|l|}
\hline Parameter & Matrix & Fracture & Unit \\
\hline Matrix dimension & $\mathrm{B}=1$ & & $\mathrm{~m}$ \\
\hline Porosity & $\phi \mathrm{M}=0.30$ & $\phi \mathrm{F}=0.30$ & \\
\hline Permeability & $\mathrm{k}_{\mathrm{M}}=1.0 \times 10^{-15}$ & $\mathrm{k}_{\mathrm{F}}=1.0 \times 10^{-12}$ & $\mathrm{~m}^{2}$ \\
\hline Residual/initial saturation & $\mathrm{S}_{\mathrm{Mr}}=0.2$ & $\begin{array}{l}\mathrm{S}_{\mathrm{Fr}}=0.01 \text { (Figs.1 \& 2) } \\
\text { or } 0.2 \text { (Fig. 3) }\end{array}$ & \\
\hline Coefficient of relative permeability & $\mathrm{C}_{\mathrm{kM}}=1.0$ & $\begin{array}{l}\mathrm{C}_{\mathrm{kF}}=0.1(\text { Figs. } 1 \& 2) \\
\text { or } 1.0(\text { Fig.3) }\end{array}$ & \\
\hline Coefficient of capillary pressure & $\mathrm{C}_{\mathrm{pM}}=1.0 \times 10^{4}$ & $\mathrm{C}_{\mathrm{pF}}=1.0 \times 10^{3}$ & $\mathrm{~Pa}$ \\
\hline Saturation at well & $\mathrm{S}_{0}=1.0$ & & \\
\hline Injection rate at well & $\mathrm{q}=1.57 \times 10^{-4}$ & $\mathrm{~m}^{3} / \mathrm{s}$ \\
\hline Fluid viscosity & $\mu_{\mathrm{w}}=1.0 \times 10^{-3}$ & $\mathrm{~Pa} \bullet \mathrm{s}$ \\
\hline Fluid density & $\rho=1,000$ & $\mathrm{~kg} / \mathrm{m}^{3}$ \\
\hline Wellbore radius & $\mathrm{r}_{\mathrm{w}}=0.1$ & $\mathrm{~m}$ \\
\hline
\end{tabular}




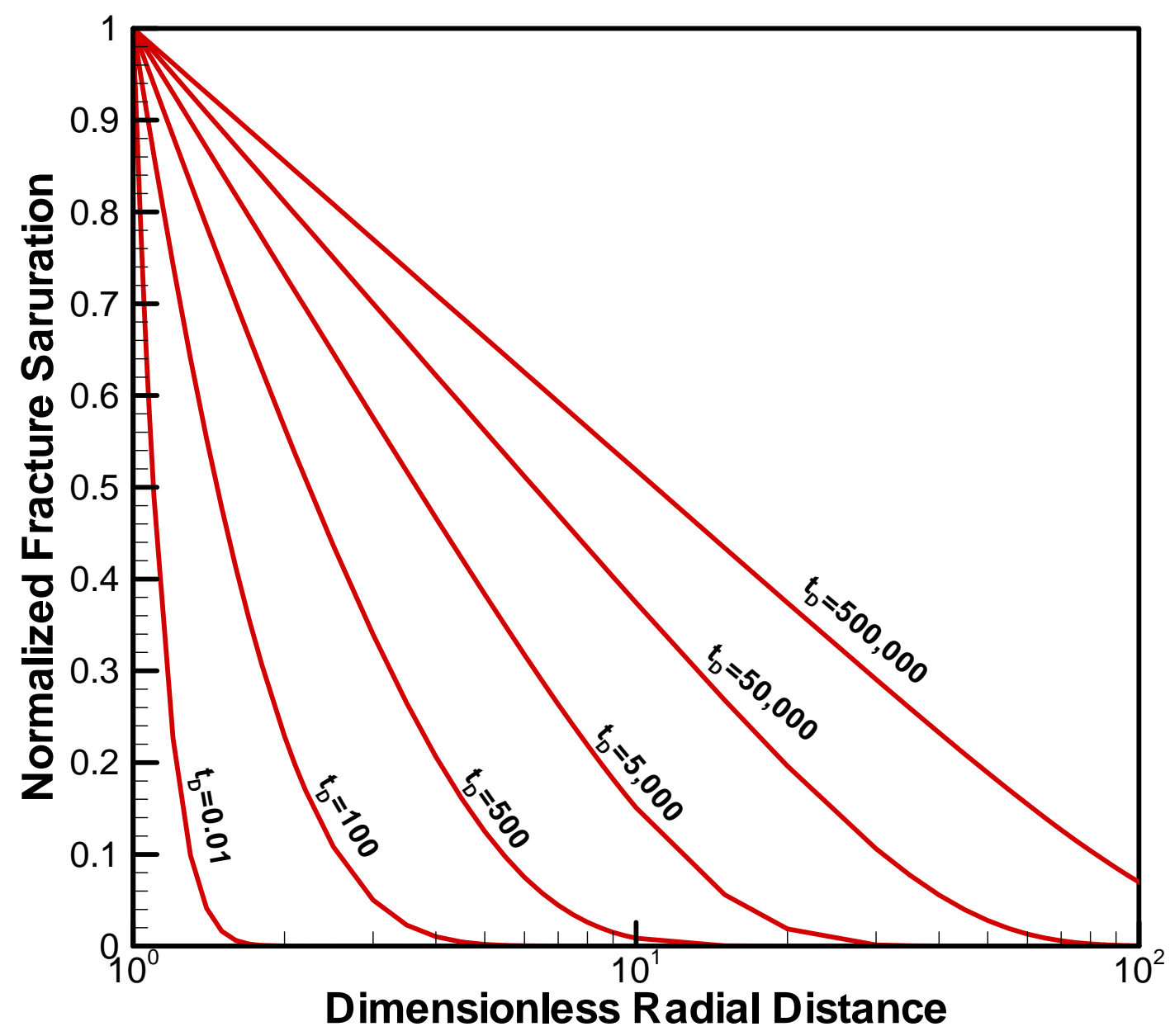

Figure 1. Type curves of normalized liquid saturation in fractures versus dimensionless radial distance at different dimensionless times, with $\mathrm{S}_{\mathrm{F}}=1$ at well 


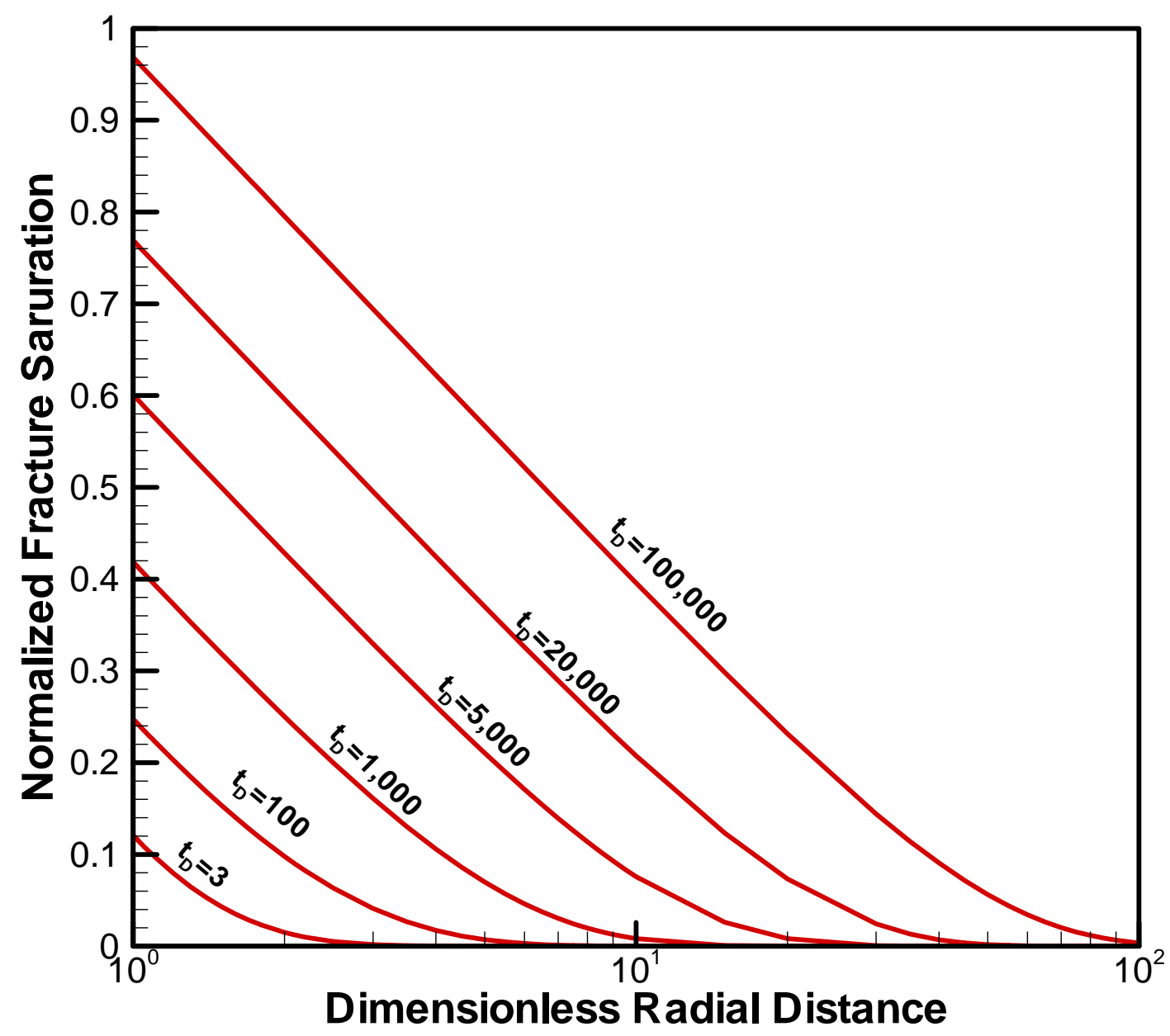

Figure 2. Type curves of normalized liquid saturation in fractures versus dimensionless radial distance at different dimensionless times, with constant injection dimensionless rate $\mathrm{q}_{\mathrm{p}}=0.25$ at wel. 


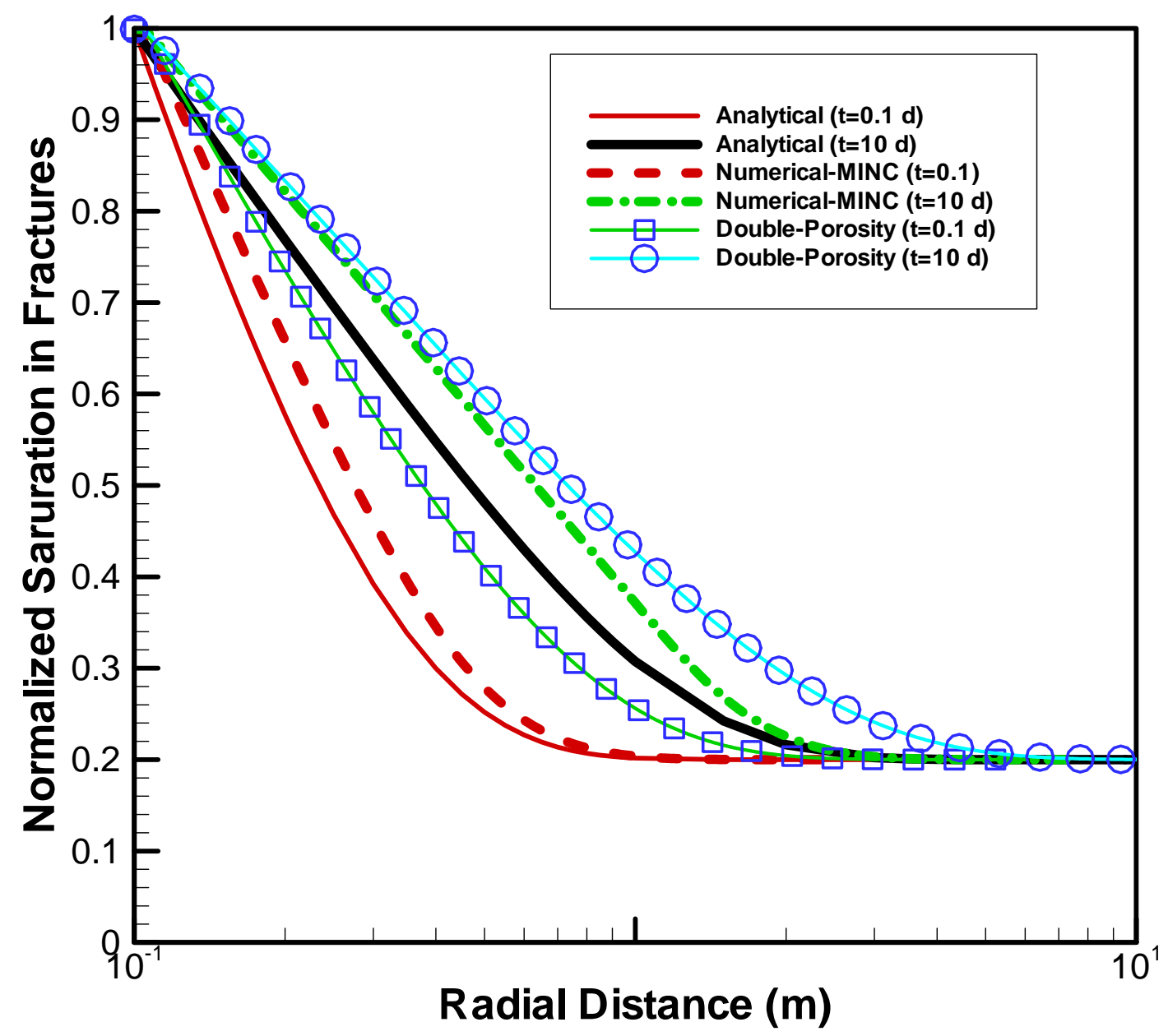

Figure 3. Comparison of fracture liquid saturations simulated using the analytical solution and numerical results with the double-porosity and MINC modeling approaches, with with $\mathrm{S}_{\mathrm{F}}=1$ at well 